\title{
Nas tramas da amizade: tensões e limites da sociabilidade em um grupo de "homens homossexuais" mais velhos, a Turma OK
}

\author{
Thiago Barcelos Soliva \\ Doutor em Ciências Humanas (Antropologia Cultural) pela Universidade Federal \\ do Rio de Janeiro; professor da Universidade Federal do Recôncavo Baiano. \\ thiago104@yahoo.com.br
}

\begin{abstract}
Resumo Este artigo se ocupa das tensões e dos "limites da sociabilidade" de um grupo de "homens homossexuais" mais velhos, a Turma OK, localizado na Lapa, bairro do Rio de Janeiro. Com mais de cinquenta anos de existência, este grupo segue promovendo eventos que reúnem um número considerável de sócios. Meu interesse aqui é compreender um aspecto significativo da sociabilidade do grupo, o conflito. O foco analítico recai nas tensões e disputas de sentidos sobre o grupo, que são negociadas no fluxo das interações entre os sócios e outros frequentadores. Também enfatizo as distintas opiniões sobre as direções que garantiriam ou não a manutenção da associação. A captura desses sentidos só é possível quando considerada a articulação entre gênero, sexualidade e geração. Os dados para a construção deste texto foram obtidos através de etnografia. As festas, os concursos e a assembleia geral de sócios foram eventos importantes para o registro desses dados.
\end{abstract}

Palavras-chave: Amizade, Turma OK, sociabilidade, sexualidades, geração.

\section{Apresentação}

$\mathrm{E}$ te artigo se ocupa das tensões e dos "limites da sociabilidade" de um grupo chamado Turma OK, formado majoritariamente por "homens homossexuais"1 com idades que variam de quarenta a setenta anos. A fundação do grupo data da década de 1960. Desde a década de 1980, a Turma OK mantém uma sede na Lapa, bairro boêmio do Rio de Janeiro. Este espaço congrega um conjunto variado de atividades, que incluem festas, reuniões, concursos e, principalmente, os shows de artistas-transformistas, através dos quais a Turma OK é reconhecida.

O objetivo deste artigo é compreender as tensões e disputas de sentidos sobre o grupo, que são negociadas no fluxo das interações entre os sócios e outros frequentadores. Também são avaliadas as distintas opiniões sobre as direções que garantiriam ou não a manutenção da associação em um contexto de segmentação do mercado dedicado à sociabilidade homossexual. Os dados para a construção do texto foram obtidos em um trabalho de campo realizado entre os dias 8 de outubro

1. Atualmente, os sujeitos que participam das atividades da Turma OK se percebem como "homens homossexuais" e "gays", mas nem sempre foi dessa forma. Nas décadas de 1960 e 1970, era a expressão "bicha" que mobilizava significados às experiências desses sujeitos. 
de 2010 e 28 de agosto de $2011 .^{2}$ Em sua maioria, os sócios da Turma OK são homens que se identificam, simultaneamente, como "homossexuais" e "gays" e possuem idades que variam entre quarenta e setenta anos. Muitos já são aposentados em algum ramo de atividade. Ainda que exista uma variedade na composição racial dos sócios, há entre eles uma predominância de homens brancos. Poucas pessoas travestis e transexuais participam das atividades do grupo. As que participam são, geralmente, convidadas por algum sócio para fazer show. Existe ainda na Turma OK um departamento feminino comandado por uma sócia, Theca de Castro, uma mulher heterossexual negra. Este departamento é encarregado da organização de determinadas agendas, como a comemoração do Dia das Mães.

A Turma OK foi fundada em 13 de janeiro de 1961, tendo completado, no período da pesquisa, cinquenta anos de existência. O trabalho de pesquisa me permitiu perceber que a trajetória desse grupo foi construída a partir das relações de amizade estabelecidas entre sujeitos com histórias de vida semelhantes. Na década de 1960, estes começaram a se reunir para compartilhar experiências relacionadas às suas sexualidades não convencionais, ${ }^{3}$ que marcaram profundamente suas subjetividades e formas de sociabilidade. Com o tempo, passaram a se perceber como integrantes de uma "família", e esta característica singular organiza, até hoje, sentidos e valores em torno da associação.

\section{A etiqueta da Turma OK}

Ser sócio da Turma OK implica atender a um conjunto de obrigações formais e informais através das quais se estruturam as relações no grupo. Além das obrigações previstas no estatuto do grupo, os sócios se deparam com etiquetas e "rituais de polidez" mais ou menos organizados que devem ser cumpridos para a manutenção dos laços de amizade entre si. Essas regras criam pontos de tensão entre distintos interesses que se expressam em várias situações.

A ideia de "vestir a camisa", ou seja, estar disponível para atender a qualquer demanda que possa surgir no tocante ao bom funcionamento do grupo é um desses pontos de tensão entre os sócios da Turma
OK. Para Benito, ${ }^{4}$ presidente do grupo na época da pesquisa, apenas pagar a mensalidade não é suficiente para um "OK". O predicativo que reputa positivamente ou não um sócio é a disponibilidade para assumir compromissos como: ficar na portaria do espaço caso o funcionário designado para isto esteja ausente, ajudar no bar em dias de muito movimento ou mesmo consumir os produtos vendidos dentro da sede. Aqueles que não correspondem a essas expectativas são considerados maus sócios. De acordo com Benito, "esse tipo de pessoa só frequenta a Turma OK para aparecer". São pessoas que participam das atividades do grupo, mas não oferecem nenhuma contrapartida. Essa interpretação de Benito está intimamente relacionada com uma hierarquia de valores sociais com os quais a Turma OK se identifica, sendo a generosidade um dos valores mais apreciados nessa escala. Suas queixas são organizadas com base na percepção de que existe um descompasso entre o que a Turma OK oferece a essas pessoas e o que elas dão em troca. Tal desequilíbrio expõe uma das lacunas dessa sociabilidade, já que coloca em xeque a ideia de "interação entre iguais" (Simmel, 1983).

Mesmo os funcionários que são contratados para trabalhar nas noites de movimento não ficam isentos da sociabilidade exigida pelo grupo. Pude ver Benito fazer vários elogios a Júnior, o rapaz da portaria. Segundo ele, Júnior está sempre disponível para fazer qualquer coisa, não apenas ficar na portaria. Diferente de Charles, rapaz que fica no caixa e que, apesar de "fazer muito bem o serviço", afirma Benito, não se dedica a casa. A dedicação, para Benito, seria mostrar solidariedade para com a instituição. Isso não quer dizer que os funcionários deveriam abrir mão do pagamento correspondente à noite trabalhada, mas estar disponíveis para mudar de função quando fosse preciso para assegurar o bom funcionamento da casa.

Quanto à atitude de consumir no bar, embora seja uma forma de colaborar com a associação, sobretudo nas noites de menos movimento, é também uma fonte de problemas para a presidência. O fato é que existem sócios que não pagam seus débitos no bar. Como os sócios podem comprar fiado, alguns não pagam o que ficam devendo, aumentando as dívidas da associação. Aqueles que não consomem nada no espaço - nem bebidas, nem aperitivos - também são vistos como problema. Eles pagam a mensalidade, mas, segundo Benito, já que não geram dinheiro, não

2. Durante esse período, a Turma OK entrou em recesso duas vezes, nas festas de Fim de Ano e no Carnaval. O recesso durou, para cada festividade, um final de semana.

3. A noção de "sexualidades não convencionais" constitui uma estratégia para evitar o uso de classificações comprometidas tanto com as antigas categorias médicas, como "homossexual", quanto com as categorias identitárias contemporâneas, como "gay", "travesti" etc.

4. Todos os nomes citados neste artigo são de pessoas publicamente identificadas com a Turma OK, seja através de jornais, revistas e livros, seja por meio do site da associação. Optei por manter os nomes verdadeiros dos informantes, com o seu consentimento, visto serem de domínio público. Somente um dos interlocutores decidiu não permitir o uso de seu nome. Respeitando sua vontade, utilizei um nome fictício para me referir a ele. 
estão contribuindo efetivamente para a manutenção do espaço.

Há ainda os sócios que não levam a sério o pagamento de suas mensalidades. Esta não assiduidade no pagamento também provoca um problema delicado entre os sócios e a presidência - uma tensão que se inscreve no projeto de cooperação firmado pelo grupo. A questão foi colocada em todas as assembleias em que estive presente: o que fazer com os sócios que não pagam? De acordo com o estatuto, essas pessoas deveriam pagar a taxa de entrada, mas como cobrar? Benito e Álvaro são a favor da cobrança, mas ambos acreditam que isso feriria o objetivo central do grupo, reunir amigos. Isso ficou claro para mim quando, por esquecimento, atrasei a mensalidade. Na noite em que fui quitar minha dívida, fui logo me desculpando pelo atraso, pois achava que isso poderia comprometer minha relação com o grupo. Contudo, Benito foi extremamente carinhoso comigo, alertando-me de que o principal ali era a presença dos sócios; o pagamento era um dado irrelevante.

Ao mesmo tempo que é considerado irrelevante, o pagamento é essencial para manter a saúde financeira do grupo. Atento para essa questão, Benito procura incentivar os sócios a levar amigos para assistir aos shows. Tendo que pagar a entrada, os visitantes geram liquidez imediata, e esse dinheiro é usado, principalmente, para o pagamento da equipe (garçom, cozinheira e porteiro) que faz o serviço de recepção e atendimento geral. Contudo, a entrada de várias pessoas diferentes na Turma OK não é encarada com bons olhos por um grupo de sócios, que acredita que essa entrada pode descaracterizar a concepção original sob a qual teria se formado o grupo.

Ascender na hierarquia do grupo parece ser outro motivo de tensões entre alguns sócios. Essas tensões se expressam por acusações feitas àqueles que se tornam presidente ou vice-presidente ou detêm outro cargo de gestão. As acusações são formuladas basicamente com base na ideia de "má gestão". São vários os exemplos de que podemos lançar mão, como o de Anuar Farah e o de Mimosa Kerr, sócios antigos que foram acusados de desvio de dinheiro. A mágoa gerada por essa acusação foi tamanha que os dois saíram do grupo e não mais voltaram, ainda que tivessem devotado grande parte de sua vida a ele.

Também não são vistos com bons olhos aqueles sócios que se "montam" e que assumem cargos de presidente e vice-presidente. De acordo com alguns sócios, os presidentes que se "montavam" perdiam muito tempo com amenidades e se esqueciam das reais necessidades da Turma OK. Quando falam desse problema, todos ressaltam Mimosa Kerr como um exemplo negativo nessa questão. Para eles, Mimosa Kerr gastava grande parte da receita destinada à ma- nutenção do espaço com o que consideram frivolidades, como festas sofisticadas, coquetéis, reuniões etc.

Essas acusações aparecem também durante a gestão de Benito, presidente atual, só que de outra forma. A preocupação de Benito em manter a casa funcionando faz com que ele direcione seus esforços para gerar dinheiro, o que incomoda alguns sócios. Muitos reclamam ainda da falta de educação do presidente na condução da casa. Fabíola Fontinele, eleita Musa OK 2010, reclamou, na assembleia geral de sócios do mês de fevereiro de 2011, da indelicadeza com que foi tratada por Benito em um evento em que chegara atrasada. Parece que Benito vem se interessando por um tipo de gestão que preza pela racionalidade e otimização. Sua atuação não preza pela polidez e pelo cuidado com as palavras, conta Anuar. Essas características fazem com que Benito seja visto por muitos sócios como rude e mal-educado.

A realização dos "projetos" também evidencia descompassos importantes na dinâmica da sociabilidade dos sócios da Turma OK. Os projetos são os shows promovidos pelos sócios do grupo. A rigor, eles são compostos pelo apresentador - o "dono do projeto" -, que coordena números de dublagem realizados por outros sócios. Cabe ao dono do projeto propor um tema, arcar com o custeio do cenário e, ocasionalmente, com a distribuição de brindes e aperitivos aos convidados. Tais projetos ligam esses homens uns aos outros através de compromissos contraídos entre si. As análises de Marcel Mauss (2005) sobre as relações estabelecidas entre o "hóspede" e o "anfitrião" são modelos significativos que podemos adotar para interpretar essa lógica. Partindo desses modelos, o convite aos que vão compor o espetáculo assume a forma de uma "prestação", como em um contrato. Seria esta a estrutura das relações entre os donos de projetos e os artistas-transformistas convidados a compor o elenco do projeto: o convite é feito ao artista pelo dono de projeto. O convidado se compromete a estar presente no dia e hora marcados para sua apresentação. O aceite e o comparecimento criam uma aliança entre os dois indivíduos envolvidos na relação. O dono de projeto contrai, a partir daí, uma obrigação com o artista que convidou. Este, por sua vez, quando da realização do próprio projeto, poderá vir a convidar aquele que o convidou primeiro.

Do ponto de vista maussiano, esse ritual de polidez produz uma relação de alienabilidade, já que na troca um sempre se põe no lugar do outro. Isso pode ser observado no palco quando um artista, após sua apresentação, agradece o convite do dono do projeto, fazendo questão de destacar a natureza da relação entre ambos - a amizade, sentimento que o teria levado até ali. O dono de projeto retribui então essa polidez com o compromisso de estar presente em um possível show que o convidado venha a organizar. 
Os atrasos e não comparecimentos às apresentações marcadas são encarados como faltas graves cometidas pelos sócios que participam dos projetos. Essas faltas são sempre fontes de divergência entre os sócios. Os atrasos criam animosidades entre os donos de projetos e seus convidados, chegando mesmo a resultar na proibição ao convidado de entrar no palco. Se os atrasos são vistos com cautela pelos donos de projeto, os não comparecimentos representam uma quebra total do compromisso firmado entre os dois contratantes. Quando isso ocorre, há um rompimento momentâneo da amizade. Esse rompimento se expressa por meio da evitação (parar de falar com a pessoa), das fofocas com outros sócios sobre o suposto descompromisso do convidado e, no limite, através de uma briga mais séria (bate-boca).

Lotar ou não o salão da Turma OK nos projetos determina o prestígio com que alguns sócios se distinguem, o que denota seu destaque na hierarquia do grupo. No entanto, ser querido por todos os sócios não significa ser um sucesso de público. É preciso ter outros atributos quando se trata de lotar o espaço, e um deles é ter prestígio também fora da Turma OK. Os shows considerados mais bem-sucedidos nesse quesito são os de Tula Morgani, Rose Christine e Magaly Penélope. Tula Morgani é um maquiador que trabalhou durante muito tempo para a Vogue Brasil, importante revista de moda. Hoje, é proprietário de um famoso salão de beleza em Copacabana. A relação com as suas clientes torna o seu projeto, Tula recebe..., um verdadeiro sucesso de audiência entre os sócios da Turma OK e também entre as pessoas de fora. O mesmo não ocorre com outros, como Denise Tainah, cujo projeto Rio Ladies, realizado toda terceira sexta-feira de cada mês, tem sofrido com o esvaziamento de público. A ausência de pessoas nos dias do seu projeto vem fazendo Denise querer desistir de mantê-lo. Percebo que Denise tem uma boa relação com os donos de projetos e os demais sócios, contudo, essa simpatia não é suficiente para conferir sucesso ao seu projeto.

Portanto, mais do que ter prestígio, os sócios têm de saber usar essa qualidade para manter o seu projeto sempre disputado pelos artistas-transformistas. Para conseguir isto, eles se envolvem todos os meses em uma verdadeira maratona, cujo objetivo é deixar o salão da Turma OK lotado. Movidos por esse intuito, acionam suas redes de amizades, por telefone, e-mail ou pessoalmente, como faz Tula, chamando as clientes do salão do qual é proprietário para vê-lo "montado" no palco. Ser bem-sucedido nos projetos implica ser disputado pelos artistas-transformistas. Tula Morgani tem sempre um número expressivo de- les à sua disposição, ao contrário de Denise Tainah. A justificativa adotada por esses artistas-transformistas é que a maquiagem, o deslocamento e o penteado são caros e demorados, e, portanto, com "um salão vazio, não vale a pena o sacrifício" das apresentações, afirma um dos sócios.

A frequência dos sócios nos diferentes projetos é outro item importante a ser respeitado na etiqueta da Turma OK. Muitas das reclamações que observei entre os donos de projeto se dirigiam à ausência de seus pares na plateia. Prestigiar o show do outro, na perspectiva desses homens, é uma "obrigação". A ausência é entendida como falta de cortesia e de reconhecimento ao trabalho que está sendo feito. A acusação a um "faltoso" é sempre tema de fofocas entre os sócios. Essa questão é constantemente levada para as assembleias. Contudo, a direção da casa alega que é impossível ter controle sobre isso. O resultado é um clima de animosidade que se materializa entre os donos de projeto e os sócios faltosos.

\section{Entre a tradição e as inovações}

Um importante ponto de tensão observado na Turma OK é a divisão entre os sócios que acham que o grupo deve se integrar mais ao "circuito gay" carioca e aqueles que acreditam que a associação deve continuar como um "clube de amigos". A ideia de "modernização" da Turma OK é defendida, por exemplo, por Wilma, secretária no período da pesquisa, e reforçada por sócios que tentam levar elementos novos para o palco da Turma OK, como as performances de gogo boys $s^{5}$ e as de top drags. ${ }^{6}$ Os que defendem a permanência do "clube de amigos" advogam a tese de que, se a Turma OK existia até o momento da pesquisa, isso se devia ao relativo anonimato que mantinha em relação à sociedade mais ampla. De qualquer forma, a tentativa de levar elementos novos para o palco da associação é observada pelo conjunto do grupo com certa reserva.

A busca de inovações evidencia um jogo de disputas importantes que conferem significados ao "estar no grupo". Tais disputas mostram como esses sócios, ainda que partindo de diferentes perspectivas, perseguem um objetivo comum: a manutenção dos laços sociais que animam o grupo.

O conflito referido ocorre de forma mais acentuada no projeto Carlos Salazar \& Company. Esse projeto lota a casa de jovens em razão de apresentar um concurso com gogo boys. Considerado um sucesso de público por Benito, o projeto de Carlos Salazar

5. Rapazes extremamente fortes que dançam e fazem striptease embalados pela música eletrônica.

6. Drag queens muito jovens cuja performance no palco singulariza-se pelo "bater cabelo", ou seja, por rodar a cabeça balançando fortemente os cabelos de acordo com as batidas de músicas eletrônicas. 
divide opiniões. Para os sócios mais antigos, como D. Nildinha, de 62 anos, a presença de homens nus no palco da Turma OK é uma falta de respeito com os presentes, ideia também compartilhada por Pedro Paz. Alguns sócios com quem conversei sobre o assunto mostraram-se favoráveis a essa "inovação", como Jorge Bharoum, que expressou da seguinte forma sua opinião: "somos gays, gay gosta de ver homem pelado, quem diz que não gosta é hipócrita.” As diferentes opiniões apontam uma tensão entre o que é considerado tradicional e as chamadas "inovações" que ocorrem na Turma OK. Essas inovações são, geralmente, trazidas por três sócios que trabalham em outros espaços do "circuito gay" carioca, como saunas e boates. São eles: Sissy Diamond, Carlos Salazar e Magaly Penélope. Os três trazem aos shows não somente strippers, mas também top drags.

Deixar ou não deixar que corpos nus masculinos se exibam no palco expõe uma hierarquia de coisas aceitáveis e não aceitáveis para a Turma OK. Para o Departamento Feminino, a nudez ocupa um lugar de menor valor nessa escala. Acredito que essa hierarquia ganha sentido por meio da trajetória de vida das mulheres desse departamento, que têm mais de sessenta anos. Todas vêm de uma geração marcada pelas interdições relacionadas ao corpo e pelo exercício limitado da sexualidade (Peixoto, 1997).

Os homens encontram-se divididos. Essa divisão revela uma distinção geracional relevante. Vale ressaltar, no entanto, que as gerações a que me refiro não são baseadas nas diferenças de idade, já que todos os sócios do sexo masculino estão concentrados mais ou menos na mesma faixa etária. Essas gerações se formam de acordo com as diferentes datas de entrada no grupo. Pude notar que os sócios mais antigos se aproximam da opinião das mulheres, exigindo apresentações "comportadas", como eram feitas no passado. A nudez, na perspectiva desses sócios, deve ser reservada a espaços específicos. Para eles, homens pelados não são problemas, desde que não estejam dentro da Turma OK. Já os sócios mais novos são mais sensíveis a uma abertura do grupo para as "novidades" do "mercado gay", incluindo shows com conteúdo mais erótico.

Entre os sócios mais antigos, pude verificar uma relação mais rígida com os valores e regras defendidas pelo grupo. Para esses homens, a percepção da associação como parte da família é ainda mais acentuada. Acredito que eles podem ser definidos pelo que Myriam Lins de Barros (1989) chama de "guardiões da memória familiar". Esses guardiões exercem a função de mediadores na manutenção da identidade do grupo. De acordo com a autora, tais indivíduos representariam o "elo vivo entre gerações" (Lins de Barros, 1989), estreitando as conexões entre o ontem e o hoje.
A tensão entre manter a tradição ou permitir que novos elementos sejam incorporados ao grupo tem várias consequências. Uma delas é o esvaziamento da casa nos fins de semana em que as apresentações são mais tradicionais. Essas apresentações não têm tanta publicidade, sendo este um dos motivos que levam o espaço da Turma OK a ficar vazio, sobretudo na sexta-feira. A frequência somente dos sócios não é capaz de lotar o espaço todos os fins de semana. Para tentar solucionar o problema, Álvaro e Benito tiveram a ideia de transformar a sexta-feira em um dia para se dançar, fazendo da pista um espaço mais valorizado que o palco. A essa concepção, alia-se outra, a de tornar a sexta-feira um dia voltado para a interação erótica. O resultado foi a chamada Noite dos Maduros, cujo apelo se dirigia àqueles homens mais velhos que apreciavam dançar e estavam à procura de outros homens para fins afetivo-sexuais. Ainda que essa programação persistisse até a data da pesquisa, a Noite dos Maduros não alcançava os efeitos esperados: as pessoas não dançavam, continuavam sentadas esperando o show, e, quando este acabava, todos iam embora.

Para alguns sócios, um dos fatores que colaboram no esvaziamento da Turma OK é a diferença de gostos musicais entre os mais jovens e os mais maduros. A opinião de Pedro Paz é a seguinte: "a coisa mais, assim, movimentada que faz sucesso na Turma OK é a música Disco, né, que é anos 70, gente! Isso faz sucesso. O rock, de repente, faz algum sucesso, mas, se você botar uma Ângela Maria, uma Dalva de Oliveira, aí o sucesso é muito maior." Na visão desse sócio, o repertório das apresentações pode prejudicar a participação dos mais jovens na Turma OK. A favor dessa participação, ele defende a realização de concursos como aquele produzido por Carlos Salazar, pois eles trariam esse público mais jovem para a casa.

Talvez o motivo pelo qual a Noite dos Maduros não deu certo tenha sido a percepção corrente entre os sócios de que a Turma OK não é um lugar para se dançar, tampouco para se conseguir um namorado. A experiência de Pedro Paz na Turma OK é elucidativa nesse sentido:

Em 25 anos, eu pessoalmente já consegui sair da Turma OK acompanhado umas quatro vezes. Ou seja, é difícil, é difícil, porque quase todo mundo se conhece e muita gente vem devidamente acompanhado. Então, e essa "lei não escrita" de não paquerar quem está acompanhado. E... deixa eu ver, em quase todas essas vezes, com exceção de uma, foram pessoas que eu conheci que não eram da Turma OK, estavam vindo para a Turma OK talvez pela primeira ou segunda vez. Então, não é um lugar bom para paqueras. Nesse sentido não é bom não. 
A ideia de que a Turma OK não é um espaço para o mercado da paquera é ainda mais forte entre os sócios mais antigos. Acredito que essa concepção também esteja relacionada, mais uma vez, com a noção de que o grupo é uma família. Sendo assim, existe entre os sócios uma espécie de tabu sexual que se estabelece através da afirmação da relação de amizade. O rompimento desse tabu implicaria, no plano simbólico, a ocorrência de uma relação incestuosa. Semelhante lógica foi observada por Carmem Dora Guimarães (2005) em relação aos "amigos que transam homens" da network que pesquisou. Essa autora percebeu que as relações sexuais antecediam as relações de amizade entre os homens que integravam a rede e aqueles que estavam fora dela. Quando a relação de amizade se efetivava, as relações sexuais deixavam de ocorrer. Claro que nem todos com quem aqueles homens transavam eram alçados à condição de amigos. A amizade só se tornava um fato quando se identificava no candidato a amigo certas afinidades socioeconômicas com o "grupo de status" a que pertenciam os integrantes daquela rede. Nessas condições, a amizade e os sentimentos concernentes à relação gerada por ela estavam intrinsecamente relacionados a processos de diferenciação social que possibilitavam aproximações e distanciamentos na escolha de amigos/amores.

Se entre os sócios da Turma OK as relações afetivo-sexuais são desestimuladas, suas relações com seus "casos" dentro da sede são obrigatoriamente guiadas por uma etiqueta bem rígida. Ainda que o Estatuto da Turma OK não se refira diretamente ao controle de comportamentos dentro do espaço, como faz o Estatuto da Gafieira (Silva Júnior, 2010), algumas normas são observadas pelos sócios quando dentro da sede. Beijos, abraços muito apertados e "amassos" são vistos com cautela pelo conjunto deles. Agildo conta que, certa vez, quando apreciava uma apresentação no palco, deparou-se com um dos sócios aos beijos com seu "caso". Segundo ele, os beijos começaram a constranger todos os presentes, incluindo ele, que tomou a decisão de interpelar o sócio, o qual parou imediatamente.

Caso semelhante ocorreu comigo, quando estava na cerimônia do Prêmio JL, no dia 30 de abril de 2011. Nesse dia, havia chegado cerca de uma hora e meia antes de começar a premiação, por volta de 22 horas e 30 minutos. Estava acompanhado do meu então marido, João. Sentamos em uma mesa abaixo do espaço reservado ao DJ. Logo que nos acomodamos, trocamos um beijo e meu acompanhante repousou o braço nos meus ombros. Percebemos então que um senhor que estava sentado em uma mesa à nossa frente olhava fixamente para nós dois. Ao retribuirmos o olhar, ele veio até nós e se apresentou. Seu nome era Caco. Pensávamos que estava querendo apenas assunto, já que o João era um personagem novo naquele espaço. Caco conversou conosco sobre várias questões: amores, problemas, traições etc. Logo ele iniciaria uma conversa que me chamou muito a atenção, já que dizia respeito ao "nosso comportamento". De acordo com ele, nossa troca de carinhos não deveria ser exposta ao público, nem mesmo dentro da Turma OK. Criticando nossa forma de demonstrar afeto, dizia que aquilo poderia nos trazer problemas futuros, que corríamos o risco até de apanhar na rua. João aborreceu-se com Caco e começou a replicar os argumentos dele. Eu apertava fortemente a mão de João embaixo da mesa para que se calasse e a situação não piorasse ainda mais. Por fim, Caco, sem conseguir obter sucesso com seus argumentos, retornou à sua mesa, visivelmente chateado.

O que aconteceu entre Caco, João e eu me deixou muito intrigado: o que era considerado um comportamento devidamente apropriado para um espaço dedicado à sociabilidade homossexual? A atitude de Caco evidencia uma tensão geracional entre ele e nós dois. Caco tem 65 anos, sua geração conviveu com uma "forte pressão de cumprimento de certas convenções sociais", diria Henning (2016). As pressões produziam sentidos sobre a homossexualidade relacionando-a à transgressão e à clandestinidade. Parece que a preocupação de Caco com a nossa "segurança" era fruto de uma trajetória marcada pelo medo de ser visto com outro homem em um jogo erótico. As "novas gerações", incluindo eu e João, seriam beneficiadas com uma "vantagem", expressão de Henning (2016): a incorporação dos ganhos decorrentes da visibilidade das sexualidades não normativas. Além da visibilidade, resultante das lutas dos movimentos organizados em prol do reconhecimento destas sexualidades, tais gerações ganharam o direito às demonstrações públicas de afeto. Sendo assim, eu e João entendíamos que não era um problema sermos vistos trocando carinhos, sobretudo porque estávamos cercados de "iguais".

Com as interdições aos sócios e clientes (embora seja um espaço declaradamente gay), a Turma OK expressa o compromisso de manter uma clientela variada. Esse compromisso se estrutura na ideia de que todos devem preservar o "respeito" dentro do espaço. A noção de respeito perpassa todas as relações construídas dentro do grupo, sendo fortemente baseada no pressuposto de que só se alcança um público heterogêneo pelo controle rigoroso das demonstrações de afeto, sobretudo entre pessoas do mesmo sexo. A partir dessa ideia é que Denise Tainah nos dá uma definição sobre a Turma OK.

É um ambiente de "respeito", [frequentado por] mulheres, homens, simpatizantes, gays e lésbicas. E em que, ao mesmo tempo, também, as músicas são muito 
mais suaves, então dá para conversar numa boa, paquerar, fazer novas amizades, isso é uma compensação. Porque na boate, porque assim, o garotão tá lá sem camisa... E aquela música, tipo, que "bate-estaca" do início ao fim, que aquele público ali que gosta daquilo, eles [Turma $\mathrm{OK}$ ] já não aguentam esse tipo de música durante muito tempo.

Denise chama a atenção para essa "diversidade" de frequentadores e, ao mesmo tempo, aponta as características que julga diferenciar a Turma OK de outros "espaços gays", sobretudo as boates. Sua definição mostra que a conservação da referida atmosfera de respeito se apoia na rejeição de dois itens, a exibição de corpos nus e as músicas eletrônicas, ambos extremamente frequentes nos "espaços gays" contemporâneos. Quanto a isto, alerta Anuar: "Nossos shows não têm nu artístico. Há várias casas para isso. Aqui não tem pornografia ou promiscuidade." Essa definição encontra apoio na forma como Pedro Paz interpreta a associação:

A Turma OK é um ambiente bastante familiar, quer dizer, não é um lugar para encontros e onde as pessoas ficam se agarrando. Jamais se pensou em fazer um quarto-escuro, ${ }^{7}$ jamais se pensou em fazer nada parecido com saunas ou exibição de filmes pornôs, nada disso. É um lugar absolutamente familiar, e nesse sentido, ela foi precursora do que está acontecendo atualmente em clubes como Tijuca Tênis Clube, que de repente faz shows e apresenta espetáculos gays. Atualmente, o concurso de beleza gay acontece em qualquer nobre salão de nobres clubes da cidade, sem problema nenhum.

A noção de "diversidade" tem implicações importantes na forma como os sócios manipulam sua identidade (Goffman, 1976). Talvez essa seja a diferença mais marcante entre a Turma OK e aqueles grupos surgidos na década de 1970 que congregavam somente "bichas", alguns ainda existentes. Aderir a um grupo como estes significa assumir determinada identidade sexual publicamente. Essa questão não é essencial para a Turma OK em função da percepção de que ela é um grupo de sociabilidade, que agrega uma diversidade de pessoas. $\mathrm{O}$ indivíduo, ao aliar-se ao grupo, não tem a necessidade de se afirmar como gay, ainda que o espaço assim se defina, já que a associação reúne diferentes identidades sexuais e expressões de gênero, incluindo muitas mulheres heterossexuais.

Pedro Paz chama a atenção também para outra questão: a visibilidade gerada pela ação desse grupo.
Para ele, a atuação da Turma OK não se limitou aos encontros entre amigos para a apreciação de shows de transformistas. As noites na OK serviram e servem para mostrar ao público mais amplo, talvez como uma espécie de "militância velada", que existem "homens homossexuais" que são de diferentes profissões, de diferentes comportamentos, de diferentes pertencimentos, mas que também são gays. A repercussão dessa ambiência de respeito se faz sentir hoje em dia nos concursos de "beleza gay" que ganham os clubes considerados tradicionais do Rio de Janeiro.

A tensão geracional que se vem discutindo é observada ainda em outras situações, sobretudo na fala de alguns sócios quando se referem ao "débito" que as gerações mais novas de gays têm com as gerações mais velhas. Anuar foi um dos principais defensores da necessidade desse reconhecimento. Assim que entrei em seu apartamento, na primeira vez em que fui entrevistá-lo, disse que me sentia muito agradecido com a oportunidade de conversar com ele, já que era um homem tão atuante para a associação. Demonstrando felicidade com minhas palavras, lembrou-me de que, se eu, naquele momento, gozava da liberdade de estar fazendo uma pesquisa sobre "homossexualidade", era porque, no passado, homens como ele existiram. $\mathrm{O}$ argumento de Anuar foi repetido em outros momentos através da fala de outros sócios da Turma OK, como Álvaro Marques. Todos esses homens reivindicam um lugar de destaque na história das lutas pelo direito à livre expressão sexual.

A cobrança desse reconhecimento muitas vezes evoca um sentimento de mágoa nas gerações atuais. Pude observar isso quando a Turma OK fez cinquenta anos, no dia 13 de janeiro de 2011. Para comemorar a data do seu jubileu de ouro, foram programadas diferentes atividades que incluíam uma missa e uma recepção em sua sede social. Anuar externou seu ressentimento de não ter visto nessa missa nenhuma atual liderança do movimento LGBT. Sua mágoa foi ainda maior pelo suposto esquecimento da data por um dos mais aclamados líderes do movimento LGBT no Rio de Janeiro, o qual ocupa um cargo ligado à defesa dos direitos LGBT no governo do Estado. ${ }^{8}$ Segundo Anuar, nem uma carta teria recebido do ativista. Cabe esclarecer que o que ele reivindica não é somente a lembrança do aniversário da Turma OK, mas antes o reconhecimento do seu lugar no processo que deu origem ao moderno movimento LGBT brasileiro. Um lugar, segundo ele, estruturante, já que teria aberto caminho a esses movimentos, como podemos perceber em sua narrativa.

7. Ele está se referindo aos dark-rooms, quartos totalmente escuros disponíveis em algumas boates gays para a "pegação". Esses espaços começaram a ganhar destaque na década de 1980, quando da entrada da cultura Club no Brasil (França, 2006).

8. Optei por não explicitar o nome deste militante, pois ele não fez parte desta pesquisa. 
É uma coisa ridícula! Você não pode se surpreender com a Turma OK, você tem que saber da existência da Turma OK, porque a Turma OK é a realidade gay brasileira. Ela é a quinta no mundo, é a quinta mais antiga. Então não pode, não pode a pessoa dizer que não sabe o que é a Turma OK. O [...], durante muito tempo que ele teve no Arco-Íris, ${ }^{9}$ nós tivemos uma aproximação muito grande. Ele sempre teve muito respeito para com a Turma OK, e a Turma OK para com o Arco-Íris. Mas nunca houve aquela história da parte das ONG de reconhecerem a Turma OK como um símbolo gay. Eles achavam que, pelo fato de nós não sermos ativistas, nós éramos qualquer coisa. Por que eles são considerados grandes ativistas, por quê? Porque recebem dinheiro do governo. Nunca a Turma OK foi reconhecida como a líder do movimento, a mais antiga, nada. Eles veem sempre a Turma OK, não só essa atual do Arco-Íris, mas, de um modo geral, essas ONG acham que nós somos um "clube de bichas velhas" que fazem show. E não é a realidade, nós não somos ativistas, mas, quando foi feita a Constituição, nós estávamos lá.

A insistência nesse débito entre gerações também sinaliza a forma como esses homens se relacionam com as outras identidades que estão abarcadas na sigla LGBT, sobretudo com as mulheres militantes lésbicas. Estas ocupariam, para eles, um lugar de pouco destaque, ou, ainda, um não lugar nas lutas travadas pelas liberdades sexuais. Segundo Anuar, enquanto eles, as "bichas", apanhavam nas ruas, elas estavam paradas dentro de casa. Essa passividade, diz ele, deveria ter sido lembrada quando esse grupo reivindicou a primazia do L sobre as demais letras do acrônimo identitário. ${ }^{10}$ Contudo, apesar dessas queixas, as mulheres lésbicas sempre estiveram presentes na história da Turma OK, desde as reuniões íntimas nos apartamentos da Zona Sul carioca.

O ressentimento não ocorre apenas entre gerações, mas marca também as relações dos antigos sócios com a instituição. Muitos deles deixaram de frequentar a sede da Turma OK por divergências pessoais com outros sócios ou por não acatarem a direção tomada pelo atual corpo gestor. No segundo encontro que tive com Anuar, ele se mostrou visivelmente emocionado quando falou da situação atual da Turma OK, uma situação lamentável, segundo ele. Anuar diz que hoje a sede não conta mais com o requinte de outrora: os garçons não sabem servir, os banheiros estão em estado calamitoso e não existem copos suficientes para atender a toda a clientela. Ele e outros sócios, como José Rodrigues, deixaram de frequentar a sede da associação em função desse ressentimento com os rumos da casa. Parece que essa mágoa com a direção atual é acentuada pela saudade deixada pelos tempos antigos, que, na visão deles, eram tempos áureos.

A mágoa atravessa ainda outras relações dentro da Turma OK, sobretudo com aqueles que lá fazem shows. Foram várias as oportunidades em que pude ouvir declarações de sócios $\mathrm{OK}$ que se mostram ressentidos com outros estabelecimentos do "circuito gay" carioca. Magaly Penélope e Lady Bynydyctha são as que mais reproduzem essa crítica. Ambas são conhecidas como da "nova geração" da Turma OK. Segundo elas, a associação vem sendo constantemente desmerecida pelos "artistas famosos" da noite gay carioca e pelo "empresariado gay". 11 Tal descrédito se expressa na falta de convites aos artistas da Turma OK para apresentações nesses espaços considerados mais modernos. Para Lady Bynydyctha, essas pessoas enxergam a Turma OK como "um bando de velhos que se vestem de mulher", evitando convidá-los, talvez, por acreditar que o tipo de show que fazem é ultrapassado para os dias atuais.

Contrapondo-se a essa desconsideração, Lady Bynydyctha faz questão de lembrar o protagonismo da Turma OK na formação de novos artistas-transformistas. Em seu show no dia 5 de junho de 2011, ela anunciou com júbilo que o ganhador do Miss Rio de Janeiro Gay havia sido maquiado, penteado e ensaiado por um dos sócios mais destacados da associação, Roberto Rossi. Essa iniciativa teria sido usada para mostrar aos presentes que a Turma OK é uma espécie de "celeiro de talentos", onde os jovens podem encontrar valiosos profissionais que os ajudem a se tornar artistas-transformistas.

A percepção corrente no "circuito gay" carioca de que a Turma OK é um grupo para "bichas velhas" não encontra correspondência na variedade etária dos frequentadores desse espaço. No geral, os sócios são homens de quarenta a sessenta anos, sendo poucos os que se encontram na faixa dos setenta anos. A percepção segundo a qual a Turma OK é um espaço para velhos evidencia a existência de diferentes noções sobre a velhice em sua interação com gênero e sexualidade. O rótulo de "bicha velha" parece exigir uma antecipação da velhice, associando-a à rejeição de certas performances de gênero, sobretudo quando

9. Trata-se de um grupo de conscientização homossexual fundado em 1993 no Rio de Janeiro. Hoje, esse grupo é o principal articulador das demandas da população LGBT no estado, organizando inclusive a Parada do Orgulho LGBT, que ocorre na orla de Copacabana.

10. Anuar está se referindo à adoção do L para abrir a sigla que dá nome ao movimento. Essa iniciativa foi deliberada durante a I Conferência Nacional GLBT, ocorrida em Brasília entre os dias 5 e 8 de junho de 2008. Na ocasião, a alteração do acrônimo GLBT para LGBT atendeu ao objetivo de valorizar as lésbicas dentro do movimento, ao mesmo tempo que este pretendia se adequar ao contexto internacional, que já adotava essa nomenclatura.

11. Estou me referindo ao conjunto dos donos de boate, saunas e outros espaços de lazer voltados para os homossexuais. 
relacionadas à prática de "se montar". Contudo, essa antecipação não é vivenciada da mesma forma por todos os "homens homossexuais", como tem mostrado a literatura.

Júlio Simões (2004), ao fazer um levantamento das literaturas internacional e nacional sobre a relação curso de vida e homossexualidade, identifica algumas possibilidades de interpretação do processo de envelhecimento com base nas contribuições das ciências sociais. Para o autor, os estudos sobre o envelhecimento homossexual reproduzem os mesmos modelos interpretativos com os quais a gerontologia constrói seu entendimento sobre o envelhecimento da população em geral.

Esses modelos são divididos em duas hipóteses. A primeira, que eu poderia classificar de a "velhice como decadência", preocupa-se em analisar as perdas decorrentes do processo de envelhecer, em especial as consequências contidas nesse processo. Essa hipótese defende o "envelhecimento precoce" de homens homossexuais. Já a segunda, que chamo de "velhice como felicidade", lança luz sobre as respostas criativas dadas pelos velhos aos problemas e estereótipos negativos reputados à velhice. Essa segunda hipótese se aproxima muito das análises de Guita Grin Debert (2004) sobre a velhice na sociedade brasileira contemporânea. O fenômeno identificado pela autora como "reprivatização da velhice" está intrinsecamente ligado a uma dinâmica que faz com que a velhice seja percebida antes de tudo como uma "opção consciente", já que os avanços da medicina e das políticas de atenção ao idoso têm deslocado a ideia de decadência para o indivíduo; a decadência não é mais atribuída ao grupo. Essa hipótese admite que a velhice é uma escolha individual vivenciada por pessoas que acham que ser velho é ter como certeza o fim da vida, e não o seu recomeço.

Simões (2004) critica a noção de envelhecimento precoce dos homossexuais, ${ }^{12}$ mas não podemos deixar de considerar a forma prematura com que esses homens são lançados à condição de velhos. Acredito que, para entender essa "antecipação", é necessário articular ao processo de envelhecimento vivenciado por esses homens outros marcadores da diferença, como gênero e sexualidade. Pensada a partir desses marcadores, a noção de velhice dentro do "circuito gay" ganha outros significados.

Em termos sumários, os estereótipos relacionados ao "velho homossexual" seriam fixados nas imagens da "tia velha", afeminada e gagá que, ao mesmo tempo, exerce o papel do "velho tarado", aquele que estaria sempre disposto a agarrar os mais jovens (Simões, 2004). Nesses dois tipos sociais, a noção de "velhice como decadência" é deslocada para aqueles homens homossexuais considerados mais femininos. O termo oposto a esses dois, "coroa", como diz Simões (2004), se aproximaria da segunda hipótese, ou seja, da "velhice como felicidade". Para o autor,

o "coroa" é um personagem de idade indefinida, mas portador dos sinais visíveis da "máscara do envelhecimento": o cabelo grisalho, as rugas, a cintura grossa, os movimentos um tanto mais lentos. O "coroa", tipicamente, parece ser o homem maduro de modos viris, que tem saúde, disposição física, apresentação pessoal e dinheiro suficiente para frequentar alguns espaços do chamado "circuito gay", encontrar amigos, beber, se divertir e também tentar a sorte no mercado da paquera. (p. 420).

O "homem maduro de modos viris" ao qual se refere Simões (2004) é o oposto da "tia velha", já que reúne características que o afastam das abominações atribuídas ao processo de envelhecer. Podemos inferir então que a alcunha de "bichas velhas", atribuída aos "okêis" no "circuito gay" carioca, não se refere necessariamente aos aspectos fisiológicos do envelhecimento. Trata-se, antes, de uma marcação simbólica que define como "velhos decadentes" aqueles homens mais afeminados que gostam de se "montar com roupas do outro sexo".

Essa lógica já havia sido observada por Néstor Perlongher (1987) entre os frequentadores do "gueto gay paulistano" da década de 1980. De acordo com esse autor, as categorias "maricona" e "tia velha" eram usadas para designar um grupo etário específico em que se localizavam os "homens homossexuais" do gueto com mais de 35 anos. Além desses dois termos, que eram adotados como sinônimos para designar um indivíduo comum, a "bicha velha", também se usava a expressão "tio" para caracterizar aqueles "homens homossexuais" mais masculinos. Perlongher chama a atenção para o fato de o "tio" não diferir em nada da "tia velha" no tocante à faixa etária. A diferença se estabelece, sobretudo, nos papéis de gênero exercidos pelos dois. As diversas formas de desempenhar estes papéis têm fortes implicações no modo como esses indivíduos se inserem na dinâmica afetivo-sexual. Enquanto o "tio" goza de um status privilegiado que lhe permite ser um "bem desejado" no mercado da paquera, a "tia" amarga a condição de "bicha velha" (afeminada e engraçada), considerada assexuada ou tarada. Sua inserção no mercado sexual é nula ou mediada por compensações financeiras.

Perlongher (1987) diz que a imagem de "tio" parece se confundir com a de "fanchono" do passado.

12. Simões (2004) elenca algumas pesquisas que revelam que a tese do "envelhecimento precoce" dos homens homossexuais não se sustenta quando são comparados aos dados de homens homossexuais e heterossexuais. O autor admite que as explicações para essa hipótese não são nada conclusivas, o que as torna repletas de interpretações modificadas em cada situação social. 
Cabe, no entanto, evidenciar as fronteiras existentes entre esses dois tipos. As distâncias ficam claras quando consideramos os objetos de prazer com que os dois se identificam. De acordo com Green (2000), o fanchono era o homem de comportamento masculino que exercia o papel de ativo nas relações sexuais com outros homens, estes mais novos e mais femininos (os "putos"). Esse personagem persegue uma feminilidade no corpo do parceiro, a fonte do seu prazer. Já o "tio", também masculino, retira de outro macho os sabores da juventude, rejeitando a feminilidade nos jogos sexuais. Contudo, as duas imagens parecem convergir para um ponto comum, a erotização do homem velho associada a certa "disponibilidade para o aprendizado", o que impede que o vínculo nessas interações se esgote na relação sexual propriamente dita.

As diferentes dimensões que envolvem o chamado envelhecimento homossexual nos oferecem elementos para pensar a noção de velhice como algo que não pode ser explicado somente a partir de seus efeitos naturais (decadência corporal, adoecimento etc.). A exemplo dos "velhos homossexuais", podemos compreender esse fenômeno como o resultado de complexas relações de marcação simbólica que movimentam diversos marcadores de produção das diferenças, sobretudo aquelas relacionadas a gênero e ao exercício da sexualidade. Sendo assim, podemos depreender que a relação velhice-homossexualidade é um tema polissêmico, cuja interpretação, que não é o objetivo deste artigo, ainda carece de pesquisas que deem conta de sua especificidade.

\section{Fofocas, concursos e divergências}

A fofoca foi, entre as Turmas de "bichas" da década de 1960, um elemento importante para a construção e propagação de classificações identitárias. Durante esse período, essa prática teria sido um condutor de debates acerca do que era "ser homossexual". As discussões se davam em torno da legitimidade dos comportamentos que poderiam ser considerados ou não para a constituição de um "verdadeiro homossexual". Entretanto, a fofoca foi também uma constante fonte de brigas e discórdias entre os homens que pertenciam a esses grupos. No ano VII do jornal $O$ Snob, em sua edição n 1 (1969), Agildo Guimarães proclama que, nessa nova fase do periódico, a fofoca não teria parte.

[O ano de] 1969 parece ser o ano das novidades, pelo menos para nós do SNOB, muita coisa nova acontecerá no decorrer desse ano. Iniciamos com um jornal mais adulto (diário oficial de contos), onde crônicas, poesias, artigos de real interesse, contos e colunismo social sadio, sem fofoquinhas, aliás, abandonadas há muito por nossos cronistas, e [sem] desenhos de figuras femininas indicando rapazes que chegam a dar um ar de gozação, mostrarão nossos propósitos de atingir uma realidade do que realmente somos. (O Snob, 1969).

Se no passado os jornais caseiros eram canais por onde escoavam as fofocas e debates das Turmas de "bichas" acerca dos assuntos considerados polêmicos, hoje, a internet vem assumindo esse lugar de destaque na publicização das informações, sobretudo pessoais, sobre os "okêis". O uso da rede virtual para fazer fofocas sobre os sócios tem gerado brigas entre esses homens. Uma das brigas mais violentas que presenciei foi motivada pela "fofoca virtual". Parece que um dos sócios teria postado no Orkut fotos comprometedoras de outro sócio. A resposta veio pessoalmente, quando aquele que se sentiu prejudicado decidiu chamar a atenção do fotógrafo. A situação encerrou-se com muitos xingamentos e agressão física. $\mathrm{O}$ sócio que teria produzido as fotos e postado na rede social estava exercendo o cargo de diretor cultural da Turma OK. Tendo-se queixado com o presidente e pedido a saída do sócio agressor, ele teve seu pedido negado, pois os dois lados foram considerados errados. Diante dessa iniciativa do presidente, o diretor cultural decidiu afastar-se da Turma OK.

Durante o período da pesquisa, adicionei ao meu perfil pessoal no Orkut e no Facebook alguns sócios e frequentadores da Turma OK. Muitos deles não permitem que suas fotos sejam vistas por qualquer pessoa. Acompanhando as publicações desses homens, pude perceber que é na internet que são postados comentários ácidos sobre os outros sócios. Geralmente, esses comentários são dirigidos às performances, consideradas malfeitas, e às roupas, tidas como exageradas, inapropriadas ou muito pobres. Como alguns desses sócios não têm familiaridade com a internet, essas informações nem sempre são de seu conhecimento. Quando ficam sabendo dos ditos maldosos a seu respeito, é através de outro sócio que os viu na internet.

A fofoca é acionada ainda, frequentemente, em ocasiões de insatisfação, como após a publicação dos resultados dos concursos e das avaliações feitas das exibições artísticas no palco. Nem sempre a coroação das vencedoras de um concurso produzido pela Turma OK é um momento de festas e celebração. São muitas as tensões que ocorrem como respostas a esses resultados, principalmente quando se considera que não foram apurados com lisura. Os gastos decorrentes da produção das roupas, maquiagem e deslocamento acentuam essa insatisfação. Pedro Paz diz que houve épocas em que os participantes faziam "loucuras" para concorrer, como vender seus carros para custear 
a roupa e a maquiagem. A quebra da expectativa em relação ao evento gera toda sorte de brigas, xingamentos e, até mesmo, agressões físicas.

As tensões chegam ao ápice quando da divulgação dos nomes das ganhadoras. Anuar conta que, em um dos concursos de que participou na condição de presidente, uma das concorrentes, tendo ficado com o segundo lugar, deixou em cima da passarela o seu troféu. Irritado com a atitude da participante, Anuar pediu aos seguranças que a jogassem na rua, com as roupas que estava vestindo. Esse episódio não é um caso isolado na história da Turma OK. As insatisfações com os resultados são regulares, e muitos casos terminam com o desligamento do concorrente da associação. Em certos concursos, quando uma candidata percebe que não ficará entre as mais votadas, ela se "desmonta" como uma forma de mostrar sua insatisfação com isto. Foi o que aconteceu no concurso Garota de Ouro, realizado durante o projeto Carlos Salazar \& Company: algumas candidatas, ao descobrirem com antecedência que não alcançariam a pontuação necessária para ficar entre os primeiros lugares, "desmontaram-se" e continuaram na sede para assistir o final da apresentação. O dono do projeto, Carlos Salazar, como resposta, anunciou no palco o ocorrido e disse estar estupefato com a profunda falta de cortesia e "espírito esportivo" delas para com os outros participantes do show.

Os conflitos que ocorrem quando da realização desses concursos revelam um lado pouco festivo da sociabilidade da Turma OK. Eles expõem os sócios e acentuam as diferenças entre eles, já queapontam, por exemplo, quem pode ou não pode pagar por um "vestido inédito" ou por acessórios que completem a performance no palco. Ouvi, de muitos sócios, críticas às roupas e maquiagens usadas por alguns artistas-transformistas. Todos esses comentários ressaltavam a aparência supostamente pouco elaborada desses artistas - "pobre", segundo me diziam - como um traço negativo para o que é considerado por eles como uma boa apresentação.

\section{Patrimônio da Lapa}

Nos últimos anos, apesar da difícil relação com as inovações trazidas por alguns de seus sócios, a Turma OK vem tentando construir uma identidade associada à noção de "patrimônio da Lapa". Essa percepção tem reflexos importantes nas relações estabelecidas dentro e fora do grupo. Um desses reflexos diz respeito ao caráter ambíguo da associação quando considerada integrante do conjunto dos espaços voltados ao público homossexual. Segundo Benito, a Turma OK não é uma boate gay. Contudo, as instituições encarrega- das de fiscalizar o comércio no município tendem a aplicar as mesmas exigências burocráticas das boates à Turma OK, causando desconforto aos sócios.

A tentativa de se tornar um "patrimônio da Lapa" tem levado o conjunto dos sócios da Turma OK a tomar medidas dirigidas ao governo do estado do Rio de Janeiro. Em uma carta escrita em junho de 2010, a associação levou ao conhecimento do governador do estado, Sérgio Cabral, um pouco da história da Turma OK, enfatizando que se tratava de uma das instituições gays mais antigas ainda em funcionamento. No fim da carta, um pedido para o governador: a concessão de um imóvel nas imediações do centro para alocar a sede da associação. $\mathrm{O}$ argumento adotado se estruturava na longevidade do grupo, uma das gerações de artistas-transformistas "mais antigas do mundo", e em sua importância para as novas gerações. Ao reivindicar para si um estatuto de patrimônio, a Turma OK busca o comprometimento do estado na preservação desse espaço.

A ideia de escrever a carta foi de um dos sócios. Ela teria o objetivo de solucionar um dos principais problemas enfrentados pela associação: a falta de um imóvel próprio. O atual imóvel, assim como o anterior, é alugado. Os gastos decorrentes do pagamento do aluguel consomem grande parte da receita do grupo todos os meses. A ideia seria receber do estado um casarão dentre as centenas de imóveis públicos que se encontram desocupados e deteriorados no centro da cidade. A reforma ficaria sob a responsabilidade do grupo, assim como a manutenção do prédio. Ao estado caberia tão somente a responsabilidade de ceder o imóvel.

O apelo da Turma OK para ser reconhecida como um patrimônio é motivo de preocupação entre alguns sócios. A iniciativa poderia romper com o "muro de silêncio" criado entre a associação e o estado. O receio desses indivíduos é de que a Turma OK se torne mais uma ONG. No entanto, acredito que a proposta da associação de ser reconhecida como patrimônio da Lapa está vinculada a uma dinâmica mais ampla: o processo de reurbanização e revitalização pelo qual passa o bairro.

Antes entendida como uma região decadente da cidade, a Lapa vem, nos últimos anos, principalmente a partir da década de 1990, sendo reapropriada como espaço de lazer e boemia, sobretudo entre os jovens. O processo de renovação urbana do bairro faz com que cresça a procura por residências no local. Um dos marcos dessa dinâmica foi a construção do condomínio Cores da Lapa, situado na Rua Riachuelo (Martins; Oliveira, 2009). Sem contar as inúmeras lojas de rua que vêm sendo abertas no bairro nos últimos anos. Grande parte das pessoas que se dirigem a esse bairro é atraída por dois fatores: a proximidade entre ele e o centro da cidade, o que facilita o acesso 
ao local de trabalho e aos equipamentos culturais ali existentes (museus, teatros, bares etc.); a inexistência de favelas nas adjacências.

$\mathrm{O}$ aumento do interesse dos turistas pela região também tem contribuído para esse processo de revitalização. Percebendo essa dinâmica, o governo do estado do Rio de Janeiro vem implantando projetos que visam desenvolver o bairro, como a criação do Distrito Cultural da Lapa. ${ }^{13}$ Esse projeto tem como foco de ação a recuperação, por meio da parceria entre serviços públicos e privados, do patrimônio imobiliário público, destinando-o a atividades artístico-culturais voltadas ao fortalecimento do turismo. ${ }^{14}$

Analisando a situação da Lapa, Martins e Oliveira (2009) chegam à conclusão de que as intervenções nesse bairro vêm alterando sua paisagem urbana e contribuindo, dessa forma, para sua progressiva incorporação à esfera do consumo. Esse processo, gradativamente, transforma as noções de "bairro boêmio" e "reduto da malandragem", imagens comumente associadas à Lapa, e povoa o bairro de mercadorias culturais dirigidas a uma elite que o vem frequentando à procura de lazer e divertimento.

Não isenta das influências desse processo, a Turma OK tem procurado alinhar-se à nova realidade desse bairro. Um exemplo disso é a sua aproximação com a imagem de outras instituições fortemente atreladas ao passado boêmio da região da Lapa, tais como o Cordão da Bola Preta, o Bar Luiz e a gafieira Estudantina Musical. Esses espaços levam consigo o que a Turma OK chama de "selo de autenticidade cultural" da região, com o qual pretende se identificar.

De certa forma, a associação já vem colhendo os frutos decorrentes desse processo. Ela começa a aparecer em alguns guias de turismo da cidade do $\mathrm{R}$ io de Janeiro, como o Guia oficial do Rio e o caderno Rio Show, do jornal O Globo. Nesse guia, a Turma Ok aparece classificada como espaço voltado à cultura, dentro do link dedicado ao turismo gay. Já no jornal O Globo, ela figura na sessão destinada ao entretenimento gay, ao lado das boates Le Boy e The Week. Em geral, os sócios não se opõem a essa aproximação, desde que ela traga mais pessoas ao espaço. Lá, segundo eles, os visitantes verão que se trata de um espaço de "respeito".

Além da tentativa de integração ao novo cenário da Lapa, a reivindicação de um espaço próprio pela Turma OK revela a necessidade desses homens de "enquadrar" a memória do grupo. Para Pollak (1989), os objetos materiais (os monumentos, os prédios etc.) são as evidências mais emblemáticas desse trabalho de enquadramento. Observe-se, por exemplo, a tentativa de Anuar quando, na sede antiga, começou a reu- nir fotos e outros objetos que remetessem ao passado da associação. Desse modo, o prédio próprio atenderia muito mais do que a necessidade de livrar-se do pagamento de aluguel. Ele representaria, no dizer do grupo, um ponto de referência, uma herança deixada às novas gerações a fim de preservarem sua memória afetiva.

\section{Considerações finais}

Este artigo tratou das tensões e disputas de sentidos relacionados a gênero, sexualidade e geração entre alguns sócios que compõem um grupo chamado Turma OK. A associação mantém para os seus sócios e clientes uma rígida norma, por meio da qual são organizadas as relações de amizade que a integram. A etiqueta que rege as interações entre os sócios se estrutura numa hierarquia de comportamentos considerados adequados e não adequados para o ambiente da sede. Dentro dessa perspectiva, os atos considerados excessivos são desencorajados pelos homens do grupo, sobretudo por aqueles que são sócios há mais tempo. A rejeição de determinados comportamentos tem relação com a ideia corrente entre os sócios de que a Turma OK é uma família e, como tal, deve ser um lugar que pode ser frequentado por qualquer pessoa, sem o risco de constranger ninguém com atitudes como beijos e amassos entre homens, por exemplo.

O movimentado calendário de festas, concursos e projetos realizados pela Turma OK deixa expostos alguns "limites da sociabilidade" desse grupo, que trazem como principal consequência o conflito (Rezende, 2001). Os vários conflitos que se configuram entre os associados evidenciam processos de diferenciação organizados pela articulação entre gênero, sexualidade e geração. Esses processos organizam hierarquias que se manifestam principalmente em situações-limites, como nos resultados dos concursos ou na habilidade para manter uma audiência cativa. Vimos que o prestígio é um componente que modela essas relações, já que define quem consegue lotar ou não a casa em dias de projeto.

\section{Referências}

DEBERT, Guita Grin. A reinvenção da velhice: socialização e processos de reprivatização do envelhecimento. São Paulo: Edusp: Fapesp, 2004.

FRANÇA, Isadora Lins. Cercas e pontes: o movimento 
GLBT e o mercado GLS na cidade de São Paulo. 2006. Dissertação (Mestrado em Antropologia Social) Universidade de São Paulo, São Paulo, 2006.

GOFFMAN, Erving. Estigma: notas sobre a manipulação da identidade deteriorada. Rio de Janeiro: Zahar, 1976.

GREEN, James Naylor. Além do Carnaval: a homossexualidade masculina no Brasil do século XX. São Paulo: Ed. Unesp, 2000.

GUIMARÃES, Carmem Dora. O homossexual visto por entendidos. Rio de Janeiro: Garamond, 2005.

HENNING, Carlos Eduardo. "Na minha época não tinha escapatória":teleologias,temporalidade eheteronormatividade. Cadernos Pagu, Campinas, n. 46, p. 341-371, jan.-abr. 2016.

LINS DE BARROS, Myriam Moraes. Memória e família. Estudos Históricos, Rio de Janeiro, v. 2, n. 3, p. 29-42, 1989. MARTINS, Gabriela Rebello; OLIVEIRA, Márcio Piñon. O que está acontecendo com a Lapa? Transformações recentes de um espaço urbano na área central do Rio de Janeiro, Brasil. In: ENCUENTRO DE GEÓGRAFOS DE AMÉRICA LATINA, 12., 2009, Montevideo. Caminhando en una América Latina en transformación. Montevideo: Universidad de la Republica, 2009. v. 1, p. 1-15.

MAUSS, Marcel. Ensaio sobre a dádiva: forma e razão das trocas nas sociedades arcaicas. In: Sociologia e antropologia. São Paulo: Cosac \& Naify, 2005. p. 183-314. O SNOB, Rio de Janeiro, ano 7, n. 1, 1969.

PEIXOTO, Clarice Ehlers. Histórias de mais de 60 anos. Revista Estudos Feministas, Santa Catarina, v. 5, n. 1, p. 148-158, 1997. Dossiê Gênero e Velhice.

PERLONGHER, Néstor. O negócio do michê: a prostituição viril em São Paulo. São Paulo: Brasiliense, 1987.

POLLAK, Michael. Memória, esquecimento, silêncio. Estudos Históricos, Rio de Janeiro, v. 2, n. 3, p. 3-15, 1989. REZENDE, Claudia Barcellos. Os limites da sociabilidade: "cariocas" e "nordestinos" na Feira de São Cristóvão. Estudos Históricos, Rio de Janeiro, n. 28, p. 167181, 2001.

SILVA JÚNIOR, João Batista. O homem na dança de salão: visões, percepções e motivações. Rio de Janeiro: Multifoco, 2010.

SIMMEL, George. Sociabilidade: um exemplo de sociologia pura e formal. In: MORAES FILHO, Evaristo (Org.). Georg Simmel: sociologia. São Paulo: Ática, 1983. (Grandes Cientistas Sociais).

SIMÕES, Júlio Assis. Homossexualidade masculina e curso de vida: pensando idades e identidades sexuais. In: PISCITELLI, Adriana; GREGORI, Maria Filomena; CARRARA, Sergio (Org.). Sexualidade e saberes: convenções e fronteiras. Rio de Janeiro: Garamond, 2004. p. 415-447. 


\title{
The plots of friendship: tensions and limits of sociability in a group of "gay men" older, the Turma OK
}

\begin{abstract}
This article deals with the tensions and "limits of sociability" of a group of "gay men" older located in the Lapa neighborhood of Rio de Janeiro, called Turma OK. With over 50 years of existence, this group continues to promote events that bring together a significant number of partners. My interest here is to understand a significant aspect of sociability of that group, the conflict. The analytical focus is on the tensions and feelings of disputes over the group traded in the flow of interactions among members and other patrons, and to different opinions and proposals on the directions that would ensure or not the maintenance of the association. The capture of these senses is only possible when considering the relationship between gender, sexuality and generation. Data for the construction of this text have been obtained through ethnography. The festivals, competitions and the general meeting were important events for recording such data.
\end{abstract}

Keywords: friendship, Turma OK, sociability, sexualities, generation.

\section{En las tramas de la amistad: tensiones y límites de la sociabilidad en un grupo de "hombres homosexuales" más viejos, la Turma OK}

\section{Resumen}

Este artículo trata de las tensiones y los "límites de la sociabilidad" de un grupo de "hombres homosexuales" más viejos situado en el barrio de Lapa de Río de Janeiro, llamado Turma OK. Con más de 50 años de existencia, este grupo sigue promoviendo eventos que reúnen a un número considerable de socios. Mi interés aquí es entender un aspecto significativo de la sociabilidad de ese grupo, el conflicto. El análisis se centra en las tensiones y disputas de sentidos sobre el grupo negociadas en el flujo de las interacciones entre los miembros y otros frecuentadores, y en las distintas opiniones y propuestas sobre las direcciones que garantizarían, o no, el mantenimiento de la asociación. La captura de esos sentidos sólo es posible cuando se considera la articulación entre género, sexualidad y generación. Los datos para la construcción de este texto fueron obtenidos a través de la etnografía. Las fiestas, los concursos y la asamblea general de socios fueron eventos importantes para el registro de esos datos.

Palabras clave: amistad, Turma OK, sociabilidad, sexualidades, generación.

Data de recebimento do artigo: 02/11/2016

Data de aprovação do artigo: 01/04/2017 